\title{
Block Copolymer Templated Chemistry for the Formation of Metallic Nanoparticle Arrays on Semiconductor Surfaces
}

Masato Aizawa and Jillian M. Buriak

National Institute for Nanotechnology, Edmonton, Alberta, and the Department of Chemistry, University Alberta, Edmonton, Alberta, Canada T6G $2 G 2$.

Contact information: E-mails: masato.aizawa@nrc.gc.ca, and jburiak@ualberta.ca

Figure S1. AFM images of $\mathrm{Au} / \mathrm{Ge}(100)$ formed from PS(20000)- $b$-P4VP(19000) loaded with $\mathrm{Au}^{\mathrm{III}}$, i.e., PS- $b-\mathrm{P}\left[4 \mathrm{VP}\left(\mathrm{HAuCl}_{4}\right)_{0.3}\right]$. The scale bars correspond to $100 \mathrm{~nm}$.

\section{Au on Ge}
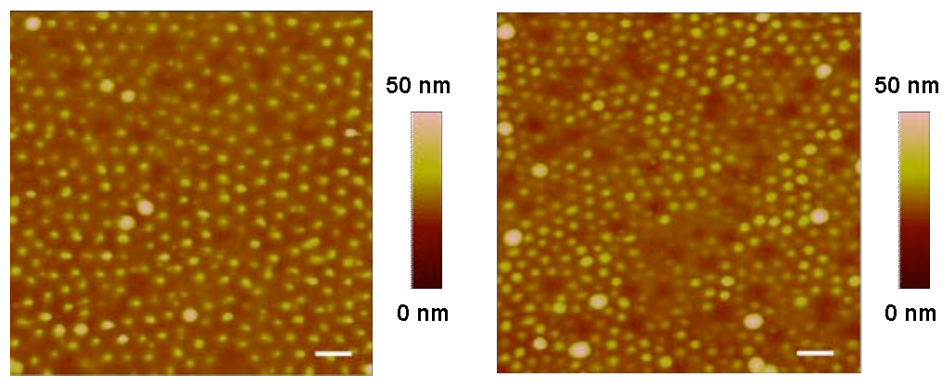

Figure S2. AFM images and line profiles for (a) PS- $b-\mathrm{P}\left[4 \mathrm{VP}\left(\mathrm{AgNO}_{3}\right)_{\mathrm{x}}\right] / \mathrm{Si}(100)$, and (c) PS- $b-\mathrm{P}\left[4 \mathrm{VP}\left(\mathrm{HAuCl}_{4}\right)_{\mathrm{y}}\right] / \mathrm{Si}(100)$ with a molecular weight of 20000-19000. The Ag and $\mathrm{Au}$ complexes are dissolved into the 4VP blocks at their solubility limits. The scale bars correspond to $100 \mathrm{~nm}$.

(a) PS-b-P[4VP( $\left.\left(\mathrm{AgNO}_{3}\right)\right] / \mathrm{Si}$
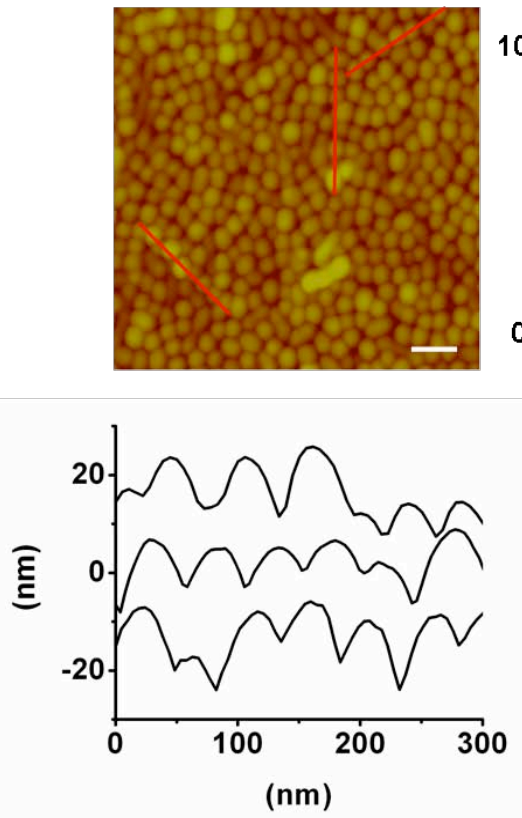

(b) PS-b-P[4VP(HAuCl $\left.\left.{ }_{4}\right)\right] / S i$

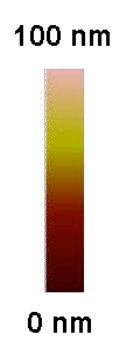

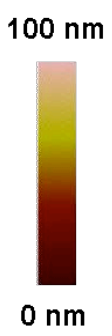

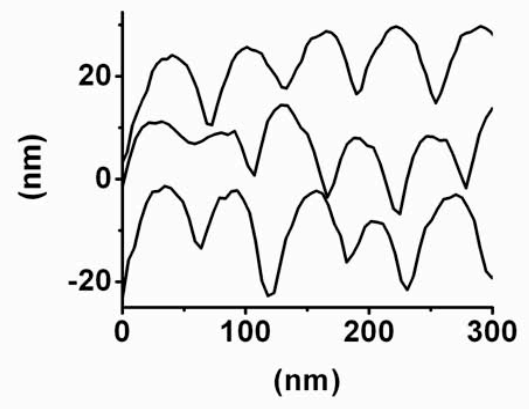


Figure S3. SEM images of (top) $\mathrm{Ag} / \mathrm{Si}(100)$ and (bottom) $\mathrm{Au} / \mathrm{Si}(100)$ prepared from PS$b$-P2VP with a molecular weight of 48500-70000. The Ag and Au depositions were carried out from $0.1 \mathrm{mM} \mathrm{AgClO} / 4.0 .225 \% \mathrm{HF}$ (aq) and $0.1 \mathrm{mM} \mathrm{KAuCl}_{4} / 0.225 \% \mathrm{HF}$ (aq), respectively, for 5 and $10 \mathrm{~min}$. The scale bars correspond to $200 \mathrm{~nm}$.

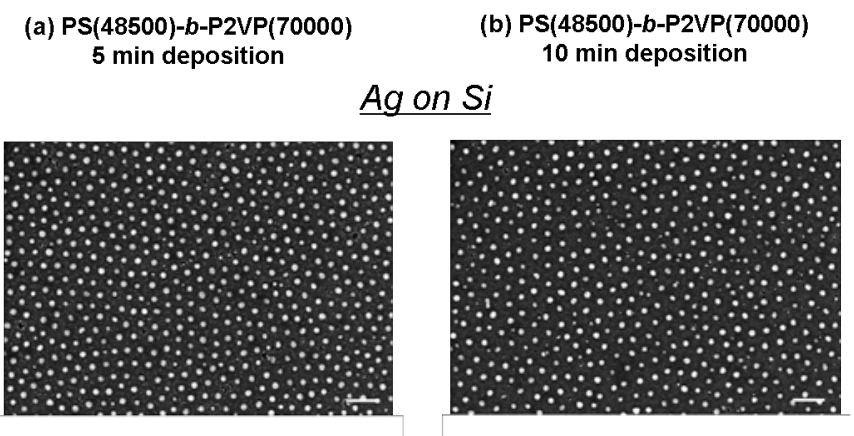

\section{Au on Si}
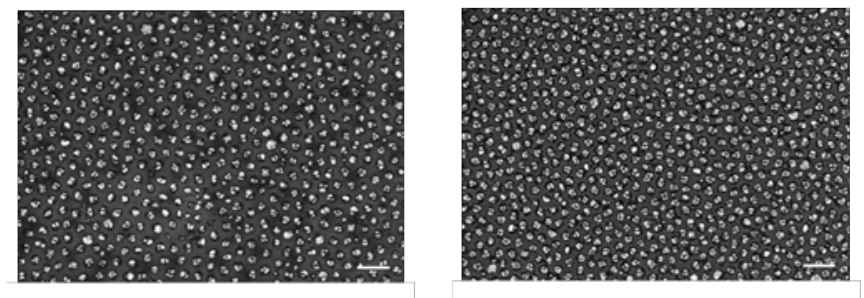

Figure S4. SEM images of (top) $\mathrm{Ag} / \mathrm{Si}(100)$ and (bottom) $\mathrm{Au} / \mathrm{Si}(100)$ prepared from PS$b$-P2VP with a molecular weight of 91500-105000. The Ag and Au depositions were carried out from $0.1 \mathrm{mM} \mathrm{AgClO} / 4 / 0.225 \% \mathrm{HF}$ (aq) and $0.1 \mathrm{mM} \mathrm{KAuCl}_{4} / 0.225 \% \mathrm{HF}$ (aq), respectively, for $1 \mathrm{~min}$. The scale bars correspond to $200 \mathrm{~nm}$.

\section{PS(91500)-b-P2VP(105000)}

1 min deposition

\section{Ag on Si}

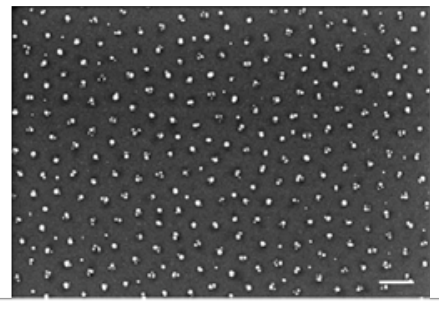

Au on Si

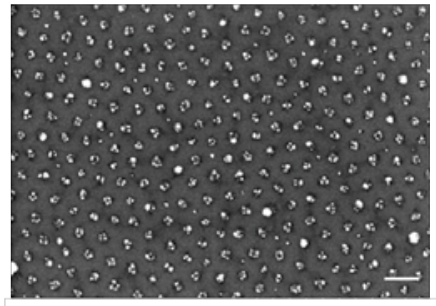


Figure S5. SEM images of (top) $\mathrm{Ag} / \mathrm{Si}(100)$ and (bottom) $\mathrm{Au} / \mathrm{Si}(100)$ prepared from PS$b$-P2VP with a molecular weight of 190000-190000. The Ag and Au depositions were carried out from $0.1 \mathrm{mM} \mathrm{AgClO} / 40.225 \% \mathrm{HF}(\mathrm{aq})$ and $0.1 \mathrm{mM} \mathrm{KAuCl}_{4} / 0.225 \% \mathrm{HF}$ (aq), respectively, for 1 and $5 \mathrm{~min}$. The scale bars correspond to $200 \mathrm{~nm}$.
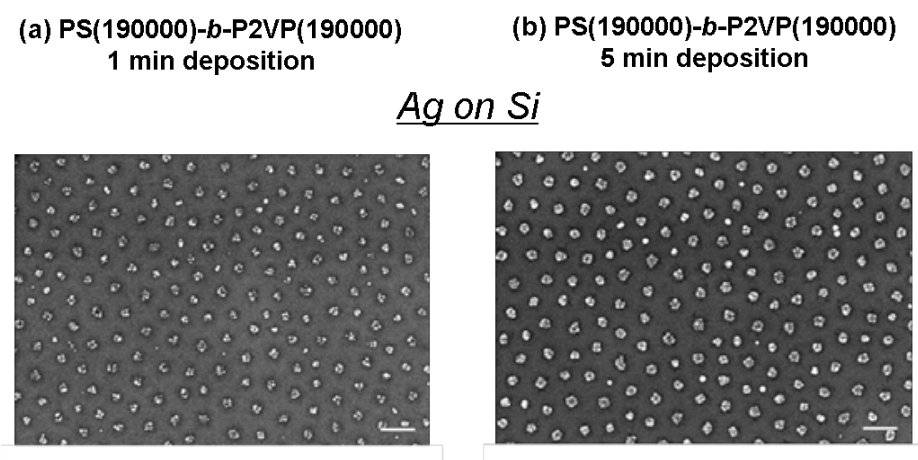

\section{Au on Si}
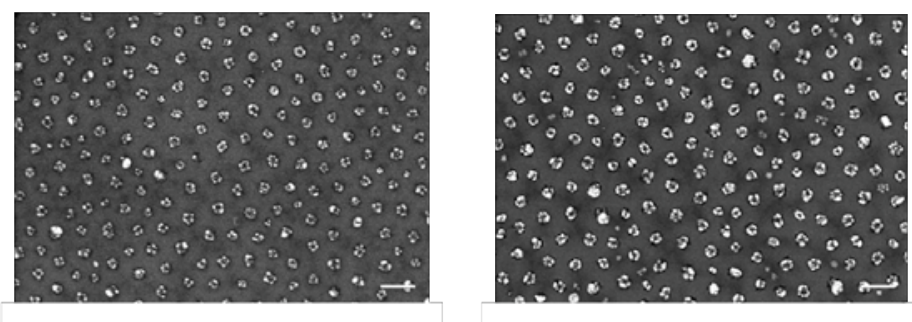

Figure S6. SEM images of Au/Si(100) prepared from PS(20000)-b-P4VP(19000). The depositions were carried out from $0.1 \mathrm{mM} \mathrm{HAuCl}_{4} / 0.9 \% \mathrm{HF}$ (aq) for 1,5 , and $10 \mathrm{~min}$. The scale bars correspond to $100 \mathrm{~nm}$.

\section{$\underline{A u}$ on Si}

(a) 1 min depostion
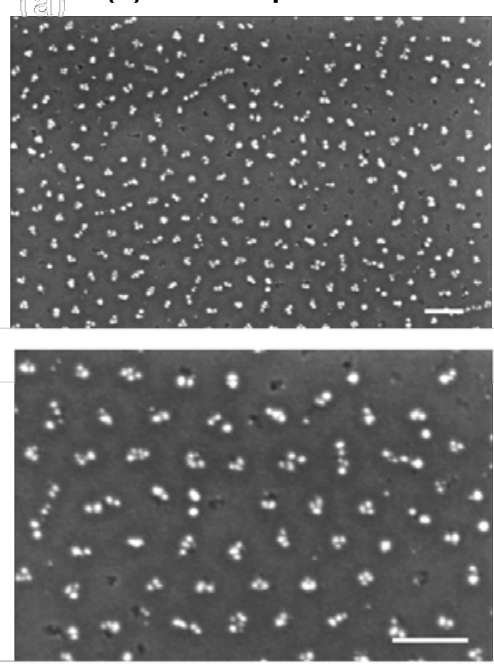

(b) 5 min deposition
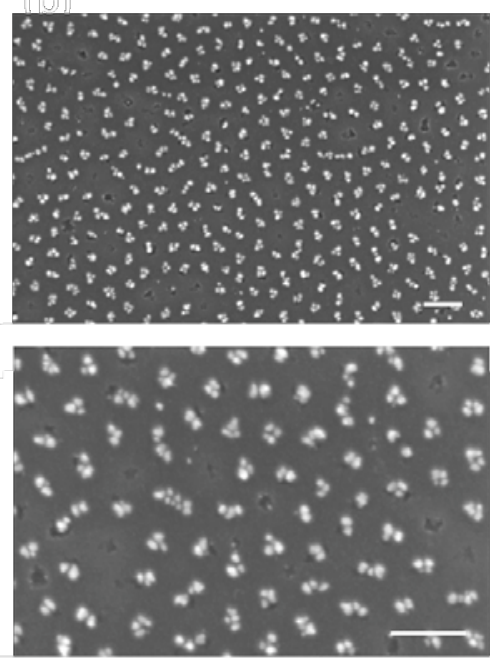

(c) 10 min deposition
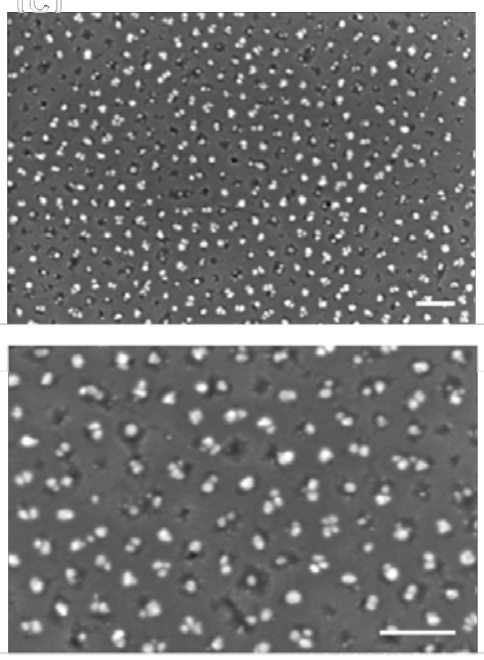
Figure S7. SEM images of (top) $\mathrm{Pt} / \mathrm{Si}(100)$ and (bottom) $\mathrm{Pd} / \mathrm{Si}(100)$ prepared without any polymer template. The $\mathrm{Pt}$ and $\mathrm{Pd}$ depositions were carried out by immersing $\mathrm{Si}(100)$ in $0.5 \mathrm{mM} \mathrm{Na}_{2} \mathrm{PtCl}_{4} / 9.0 \% \mathrm{HF}$ (aq) and $0.5 \mathrm{mM} \mathrm{Na}_{2} \mathrm{PdCl}_{4} / 9.0 \% \mathrm{HF}$ (aq), respectively, for 1,10 , and $30 \mathrm{~min}$. The scale bars correspond to $100 \mathrm{~nm}$.

(a) 1 min deposition

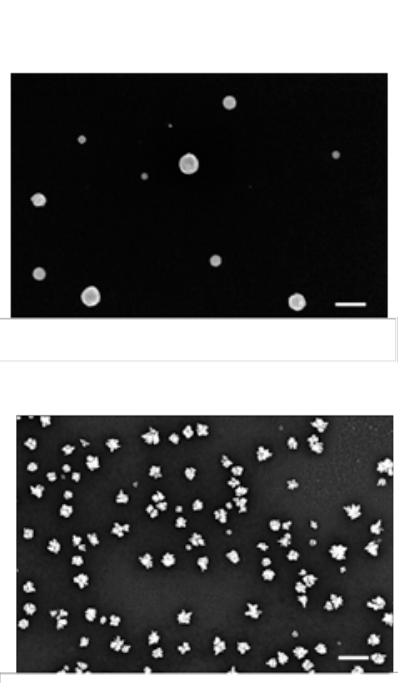

(b) 10 min deposition

Pt on Si

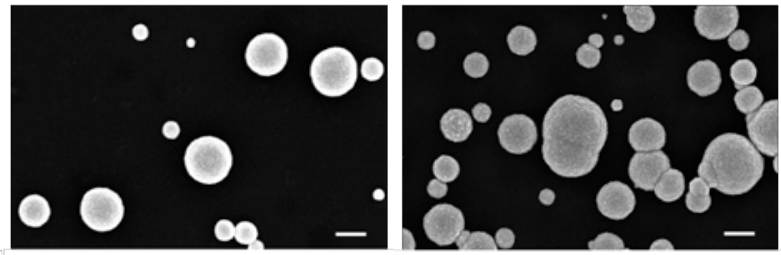

$\underline{P d}$ on Si

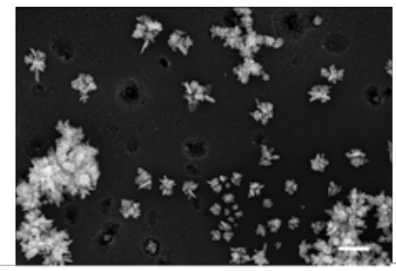

(c) 30 min deposition

Figure S8. SEM images of (top) $\mathrm{Ag} / \mathrm{Si}(100)$ and (bottom) $\mathrm{Au} / \mathrm{Si}(100)$. Prior to deposition, $\mathrm{Si}(100)$ coated with PS(190000)- $b$-P2VP(190000) was immersed into $0.25 \% \mathrm{HF}(\mathrm{aq})$ for 5 min and dried in ambient air overnight. The $\mathrm{Ag}$ and $\mathrm{Au}$ depositions were carried out in $0.1 \mathrm{mM} \mathrm{AgClO} / 40.225 \% \mathrm{HF}\left(\mathrm{aq}\right.$ ) and $0.1 \mathrm{mM} \mathrm{KAuCl}_{4} / 0.225 \% \mathrm{HF}$ (aq), respectively, for 1 and $5 \mathrm{~min}$.

(a) 1 min deposition

(b) 5 min deposition

\section{Ag on Si}
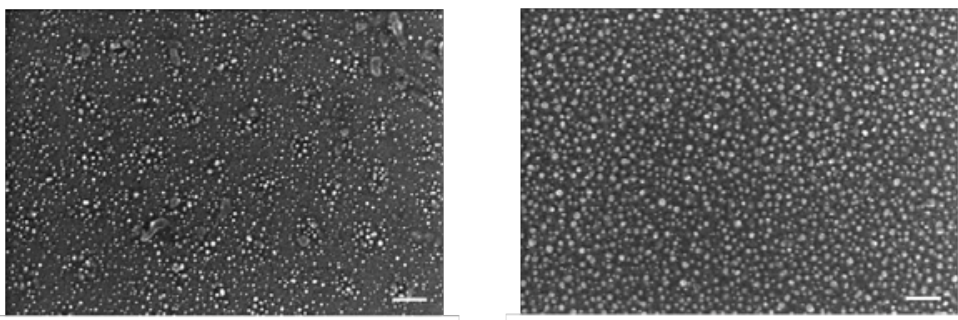

Au on Si
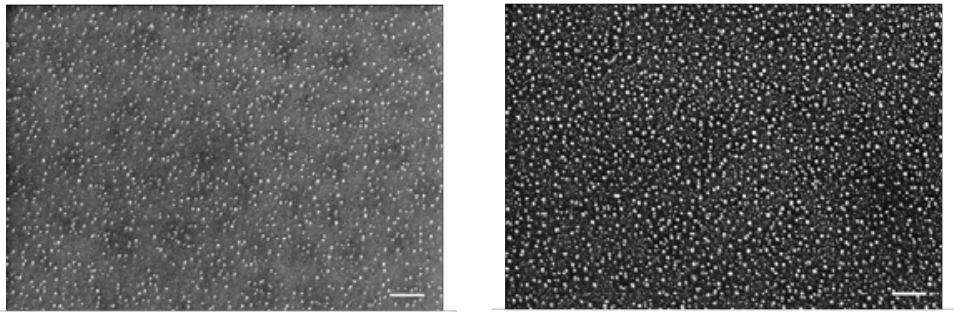